\title{
The Learning Organisation: A Means of Facilitating Training for Change in South African Organisations
}

\section{F W Struwig and E E Smith}

Department of Business Management, Vista University, Port Elizabeth

\section{J L Venter}

Institute for Statistical Consultation and Methodology, University of Port Elizabeth

\section{ABSTRACT}

This article considers the nature and role of the leaming organisation as a means of implementing change through training in South African organisations. The paper is based on theoretical study and empirical research, including 365 training and organisational development specialists in South Africa. Five nullhypotheses were empirically tested in order to establish relationships between the learning organisation and certain independent variables (classification data and training). Advanced statistical methods, such as analysis of variance and correlation coefficients were used to test these hypotheses. The learning organisation facilitates leaming by all its members and has the capacity to adapt and change continuously. If learning is an organisational priority, training programmes should be designed to promote initiatives to change the organisation. Emphasis should be placed on both leaming (acquiring knowledge and skills) and doing (practical application).

JEL M 14

\section{INTRODUCTION}

This article focuses on the nature and role of the leaming organisation as a means of facilitating training for change in South African organisations. Mabey and Salaman $(1995: 315)$ are of the opinion that the idea of the leaming organisation has flourished as one way of "summing up the sorts of organisational qualities called for and valued in today's changing environment". Hendry, Johnson and Newton, (1994: 229) and Lessem (1991: 17) concur that the leaming organisation is heralded as the organisation of the future which calls for a new management order, because of the onset of unprecedented rates of change. Althougb McSween (1995: 6) is of the opinion that creating the 
learning organisation is simple, Solomon (1994: 56) argues that "an organisation never becomes a learning organisation, because by definition it means always evolving, always being in flux, always learning". The leaming organisation is therefore a philosophy that alters the way an organisation thinks about learning and decision-making. Noer (1997: 176) also postulates that organisations of the future will not survive without becoming communities of learning, and that the learning organisation "is no academic fad or consultants' buzz word". The way in which the organisation learns can be the key to innovation, profitability and competitiveness. This article first gives a theoretical overview of the role of the learning organisation in facilitating change in the organisation through training. This is followed by a brief outline of the research method. The main survey results and conclusions, and managerial implications of the study are then provided.

\section{A THEORETICAL OVERVIEW}

According to Senge (1997: 14), the learning organisation can be described as an organisation "that is continually expanding its capacity to create its future". Swieringa and Wierdsma (1992: 71) contend that the learning organisation has, on the one hand, mastered the art of adapting quickly and, on the other hand, preserved its direction and identity. The learning organisation can therefore be considered as the involvement of all employees in the organisation in identifying and solving problems, which enables the organisation continuously to experiment and improve its capacity to deliver new products and services to customers (Hellriegel \& Slocum, 1996: 680).

It appears, therefore, that the learning organisation facilitates the process of learning by all its members and has the capacity to adapt change continuously. Marx (1997:1), however, stresses that a learning organisation is not just a programme to be implemented, but a philosophy aimed at creating, mastering and transferring knowledge. Having identified what the learning organisation is, it is necessary to clarify the concept of "organisational leaming." Both Argyris (1994: 123) and Dawson (1992: 230) assert that an organisation learns through individuals acting as agents of the organisation and is usually associated with notions of radical change. As individuals learn new ways of behaviour and develop new values, organisations, being collections of people, can also learn and develop new assumptions, values and behaviour. It is, therefore, the individuals in the organisation who enable it to learn ways that facilitate organisational change. 


\subsection{Nature of Organisational Learning}

According to Beardwell and Holden (1994: 278), it is important to understand the process and nature of learning in order to facilitate the learning and development of individual employees and, ultimately, the organisation itself. The process of learning knows no boundaries. People bring the results of this naturally occurring and continuous process to the workplace, and thus have the potential to contribute to skills, attitudes and creative thinking which organisations need to survive in a changing world.

Hendry et al., (1994: 230) argue that, at the broadest level, organisational learning is how organisations change. This, however, does not imply that organisational learming is simply about the management of change, but rather about elements and processes by which organisations develop and grow. Organisational learning is built on three key precepts: organisations learn through individuals, organisational learning is greater than the sum of individual learning, and it is a process of change in behaviour, beliefs, systems and structures. Both Argyris (1994: 8) and Dawson (1992: 230) advocate two approaches to organisational learning: single-loop and double-loop learning. Single-loop learning occurs when errors are corrected, using past routines and present policies. It involves improving organisational capacity to achieve known objectives, and the organisation is learning without significant change in basic values and assumptions (Robbins, 1996: 734). Double-loop learning means that the learning organisation corrects errors by modifying its objectives, policies and routines. This type of learning involves changing the organisation's culture (Luthans, 1995: 41). It correlates with Senge's (1997: 14) classification of adaptive learning (single-loop learning) and generative learning (double-loop learning). For the learning organisation, adaptive learning must be joined with generative learning (the capacity to create).

Marquardt (1997: 2) postulates that organisational leaming must equal or exceed the rate of change in the macro-environment, otherwise the organisation will die. Organisational leaming shows the following common characteristics:

* It enhances intellectual and productive capacity gained by organisationwide leaming.

* It builds on shared values, memory and knowledge.

* It functions like an orchestra.

* It applies system-wide learning.

Gordon (1996: 45), on the other hand, highlights some managerial implications of organisational learning. Managers must ensure that appropriate conditions for learning exist and must reinforce desired learning-based behaviour. The 
provision of environmental cues which encourage leaming, and a physical and an emotional climate supportive of leaming, is essential. Solomon (1994: 56) emphasises that organisational learning provides an opportunity for human resources to exceed the limits of training and to move further into the organisation. The learning organisation requires organisational learning in addition to traditional training.

\subsection{Characteristics of the Learning Organisation}

Mabey and Iles (1994: 24) maintain that although each organisation is unique and has its own identity, the learning organisation is an idealised state (a state of being, not just of doing). Learning and working become synonymous. As a central activity, the process of transformation enables the organisation to search for new ideas, problem-solving techniques and opportunities of leaming inside and outside the organisation. Figure 1 depicts some of the basic characteristics of a leaming organisation.

\section{Figure 1 Characteristics of a learning organisation}

\begin{tabular}{|c|c|c|}
\hline $\begin{array}{l}\text { LEADERSHIP: } \\
\text { - Shared risk-taking } \\
\text { Employee } \\
\text { empowerment }\end{array}$ & & $\begin{array}{l}\text { ORGANISATION } \\
\text { DESIGN: } \\
\text { - Teams } \\
\text { - No boundaries } \\
\text { - Few "bosses" }\end{array}$ \\
\hline $\begin{array}{l}\text { CULTURE: } \\
\text { - Sense of community } \\
\text { - Caring for workers } \\
\text { - Trust }\end{array}$ & $\begin{array}{c}\text { THE } \\
\text { LEARNING } \\
\text { ORGANISATION }\end{array}$ & $\begin{array}{l}\text { ENVIRONMENT: } \\
\text { - Open and interactive } \\
\text { - Advanced technology } \\
\text { - Participative } \\
\text { - Learning climate }\end{array}$ \\
\hline $\begin{array}{l}\text { INFORMATION } \\
\text { SHARING: } \\
\text { - Open } \\
\text { - Timely } \\
\text { - Accurate }\end{array}$ & & $\begin{array}{l}\text { STRATEGY: } \\
\text { - Focus on customers } \\
\text { - Creation of new markets } \\
\text { - Investment in emerging } \\
\text { opportunities }\end{array}$ \\
\hline
\end{tabular}

Source: Hellriegel and Slocum (1996: 681)

In addition to these basic characteristics, Mabey and Iles (1994: 25) and Pedler, Burgoyne and Boydell (1991: 18) characterise the learning organisation as one which implements the following: 
- learning strategies

- participative policy-making

- information technology to empower people

- internal exchange

- reward flexibility

- enabling structures

- frontline workers as environmental scanners

- inter-organisational learning

- a learning climate

- self-development for all.

It is, however, important to note that implementation of all these actions does not necessarily mean that an organisation is a learning organisation. Learning must be at the core of all operations. Table 1 illustrates the difference between a traditional versus a learning organisation.

Table 1 Traditional versus learning organisations

\begin{tabular}{|l|l|l|}
\hline Function & Traditional organisations & \multicolumn{1}{|c|}{ Learning organisations } \\
\hline $\begin{array}{l}\text { Determine overall } \\
\text { direction }\end{array}$ & $\begin{array}{l}\text { Vision provided by top } \\
\text { management }\end{array}$ & $\begin{array}{l}\text { Shared vision emerges from } \\
\text { various places }\end{array}$ \\
\hline $\begin{array}{l}\text { Formulation and } \\
\text { implementation of }\end{array}$ & $\begin{array}{l}\text { Top management decides } \\
\text { what must be done and the rest } \\
\text { of the organisation follows }\end{array}$ & $\begin{array}{l}\text { Takes place at all levels } \\
\text { within the organisation }\end{array}$ \\
\hline Conflict resolution & $\begin{array}{l}\text { Through power and } \\
\text { hierarchical influence }\end{array}$ & $\begin{array}{l}\text { Collaborative learning and } \\
\text { integration of diverse } \\
\text { viewpoints }\end{array}$ \\
\hline $\begin{array}{l}\text { Leadership and } \\
\text { motivation }\end{array}$ & $\begin{array}{l}\text { Leader establishes vision, } \\
\text { provides rewards and } \\
\text { punishments and maintains } \\
\text { overall control }\end{array}$ & $\begin{array}{l}\text { Leader builds shared vision, } \\
\text { empowers personnel, encou- } \\
\text { rages effective decisionma- } \\
\text { king and inspires commit- } \\
\text { ment through charismatic } \\
\text { leadership }\end{array}$ \\
\hline
\end{tabular}

Source: Adapted from Luthans (1995: 45)

From Table 1 it appears that the learning organisation is a remedy for the fundamental problems inherent in traditional organisations. Robbins (1996: 735) attests to the fact that no organisation has, or probably ever will, successfully achieve all the characteristics described above. Organisations should strive towards these ideals, rather than see them as a realistic description of structural activities. Several specific organisational characteristics serve as 
variables in this study. These include: size of the organisation as measured by the number of employees, the existence of a fully developed training department and type of environment in which the organisation operates. From the aforementioned, the following three hypotheses are formulated:

$\mathrm{H}_{01}$ The number of employees (size of organisation) is not related to the learning organisation.

$\mathrm{H}_{02}$ There is no relationship between an organisation that has a fully developed training department and the learning organisation.

$\mathrm{H}_{03}$ There is no relationship between the environment in which an organisation operates and the learning organisation.

\subsection{Creating a Learning Organisation}

Pedler et al., (1991: 49) and Fisher and Torbert (1995: 108) stress that although building a learning organisation is a challenge and that there is no single, guaranteed way of becoming a leaming organisation, there are, however, some guidelines and directives to be followed at the beginning of this joumey. Tobin (1993: 178) argues that to effectively bring the leaming organisation to life, a series of nine action steps is required:

- Study learning organisations and decide if this is the direction that the organisation wishes to follow.

- Determine the readiness for starting a learning organisation - assess the current status in terms of leadership, basic skills and teamwork.

- Prepare for the "birth" of the leaming organisation - develop plans to build it.

- Conception - with the plans in place, it is time to announce the new direction and to inform all employees throughout the organisation.

- Provide sufficient training in each identified area of skill - allow workers to practice those new skills and to learn from mistakes.

- "Kick-start" the programme - management must be clearly committed to demonstrate the seriousness of the new approach.

- Institute a series of learning practices - inculcate employees' thinking with the values of the learning organisation.

- Encourage and reinforce learning - newly-learned skills and information should be applied to the job situation and employees should be given responsibility for mastering the new skills.

- Be open to new emerging ideas - allow employees freedom to learn and share ideas. 
Such stepwise action indicates a long road to success in creating a learning organisation. Establishing a strong sense of urgency and shared commitment about becoming a learning organisation is of the utmost importance. Wick and Leòn (1993: 126) devised a formula for creating a learning organisation, which is presented in Figure 2.

\section{Figure 2 Formula for creating a learning organisation}

\section{Learning Organisation $=$}

Leader with vision + Plan/metrics + Information + Inventiveness + Implementation

Source: Wick and Leòn (1993: 127)

Employing this basic formula will create a unique learning organisation. If one element is missing, the organisation will either learn the wrong lessons or do so at a rate less than its full potential. A leader with a clearly defined vision, detailed and measurable plans of action, rapid information-sharing, inventiveness and the ability to implement the plan, is the agent who creates a learning organisation.

According to Swieringa and Wierdsma (1992: 80), there are two basic approaches to becoming a learning organisation. The "tourist model" first establishes the precise direction the organisation should follow and how to reach its destination, and only then sets out (think first, act later). The "trekker model" again suggests that the organisation, though not knowing exactly where it is heading, chooses a certain direction and then sets forth. Organisational change takes place in the form of a common, collective learning process. Using the "trekker model" implies that change takes place faster and that there is little time to establish its precise direction and destination. Mabey and Salaman (1995: 349) highlight five development phases of the learning organisation (refer to Figure 3).

Figure 3 Development phases of a learning organisation

$$
\begin{array}{ll}
\text { Transformation } \rightarrow \text { Transfiguration } \rightarrow & \begin{array}{l}
\text { Learning } \\
\text { organisation }
\end{array}
\end{array}
$$

Foundation $\rightarrow$ Formation $\rightarrow$ Continuation $\rightarrow$ Organisational learning

Source: Adapted from Mabey and Salaman (1995: 349) 
The three lower parts of Figure 3 represent the initial phases of organisational learning. The foundation phase concerns basic skills development and enthusing learners to learn more. The formation phase encourages and develops skills of self-learning and development (individual begins to leam about the organisation as a whole and its purpose). In the continuation phase, the learner and organisation become more independent, innovative and confident. The two parts in the upper section of the model are evidence of a transition from organisational learning to the learning organisation. Transformation illustrates a complete change in the form, appearance and character of the organisation. Idealisation is the focal point during the transfiguration phase of the leaming organisation. The organisation represents a way of life to be cherished because of its values. An organisation can thus progressively develop into a learning organisation.

\subsection{Lifelong Learning}

Authors like Beardwell and Holden (1994: 280) and Morton (1994: 126) advocate the inculcation of a lifelong learning culture in the organisation, to meet a continuous need for learning. Longworth and Davies (1997: 22) define lifelong learning as "the development of human potential through a continuous, supportive process which stimulates and empowers individuals to acquire all the knowledge, values, skills and understanding they will require throughout their lifetimes and to apply these with confidence, creativity and enjoyment to all roles, circumstances and environments." People continue learning throughout life, which implies continuous adaptation. Senge (1997: 4) maintains that learning organisations are possible because all people are learners. Learning is a basic characteristic of human nature and people enjoy it. Increased knowledge and improved skills enlarge the individual's capacity to adapt to the environment and to change it, if possible. Managers and agents of change must therefore cultivate a learning culture in the organisation, which implies that the individual learns throughout its life in the organisation.

\subsection{The Role of Training in the Learning Organisation}

Greenberg and Baron (1997: 92) argue that training is a systematic approach to incorporating learning in the organisation. Training can be used to prepare employees to meet the challenges and changes in the workplace and to upgrade and refine skills. The best training programmes often use many different approaches, thus ensuring that several learning principles are incorporated into training. In order to accomplish this, Harrison (1998: 33) states that trainers need a paradigm shift to introduce a new framework for coping with rapid organisational change. Learning cannot be made a purely individual responsibility. It is a corporate process involving organisation, team and 
individual. Table 2 highlights the evolution of training in a learning organisation.

\section{Table 2 Evolution of training in a learning organisation}

\begin{tabular}{|c|c|}
\hline Traditional training & Organisational learning \\
\hline $\begin{array}{l}\text { Employees receive skills training and } \\
\text { executives development training. }\end{array}$ & $\begin{array}{l}\text { All employees receive leaming support - } \\
\text { lifelong development. }\end{array}$ \\
\hline $\begin{array}{l}\text { Training goals are based on requests by } \\
\text { users. }\end{array}$ & $\begin{array}{l}\text { Learning goals are based on corporate } \\
\text { strategy and users' needs. }\end{array}$ \\
\hline $\begin{array}{l}\text { Training primarily addresses immediate } \\
\text { needs. }\end{array}$ & Learning focuses on core competencies. \\
\hline $\begin{array}{l}\text { Training is conducted locally or in an } \\
\text { offsite classroom. }\end{array}$ & $\begin{array}{l}\text { Education takes place at the workplace, job } \\
\text { site or elsewhere. }\end{array}$ \\
\hline $\begin{array}{l}\text { Delivery of training is scheduled on a } \\
\text { periodic basis. }\end{array}$ & $\begin{array}{l}\text { Delivery of education is on time, upon } \\
\text { request. }\end{array}$ \\
\hline Training is instructor-driven. & Education is self-directed. \\
\hline $\begin{array}{l}\text { Training approach is that of delivering } \\
\text { knowledge. }\end{array}$ & $\begin{array}{l}\text { Education approach is to design leaming } \\
\text { experiences or workplace interventions. }\end{array}$ \\
\hline $\begin{array}{l}\text { Content is generalised and developed by } \\
\text { training specialists. }\end{array}$ & $\begin{array}{l}\text { Content is specific and applied, and } \\
\text { developed jointly with trainees. }\end{array}$ \\
\hline $\begin{array}{l}\text { Trainers develop and deliver content, } \\
\text { trainees are recipients. }\end{array}$ & $\begin{array}{l}\text { Educators facilitate the process and coach } \\
\text { leamers - leamers are joint developers. }\end{array}$ \\
\hline $\begin{array}{l}\text { Needs assessments are carried out by a } \\
\text { training group or managers. }\end{array}$ & $\begin{array}{l}\text { Needs assessments are carried out jointly } \\
\text { by individuals, managers and training } \\
\text { groups. }\end{array}$ \\
\hline
\end{tabular}

Source: Adapted from Solomon (1994: 64)

Table 2 shows that the learning organisation requires organisational learning in addition to traditional training. Mabey and Salaman (1995: 320) state that one of the elements of the learning organisation profile is training programmes designed to support the change strategies and values held by top management. If learning is an organisational priority, training programmes should be designed to emphasise both learning (acquiring knowledge and skills) and doing (practical application). Bencivenga $(1995 ; 69)$ states that through learning and training in the organisation, employees' capacity to act and organisations' ability to adapt quickly, are enhanced. Dobson and Tosh (1998: 66) also point out the benefits of training an organisation to become a learning organisation. The stress should be on training which seeks organisational objectives to be cascaded to departmental objectives and then transformed into training objectives. According to Jones and Mann (1992: 207), training should contribute to the development of the innovative capacity of the learning organisation. Changing 
times are forcing trainers to reconsider their role in the organisation. Initially, training within organisations largely focussed on specific, well-defined skills which employees needed to improve job performance. Although this type of training remains important in the learning organisation, additional types of training are needed in order to empower employees and seek their participation. Based on this reasoning and background, the following two hypotheses are formulated:

$\mathrm{H}_{04}$ There is no relationship between the facilitating role of training and the learning organisation.

$\mathrm{H}_{05}$ There is no relationship between the role of training in managing organisational change and the learning organisation.

In the learning organisation, where employees are expected to invent their own procedures and empowered to try new ways of operation, the "old" training technology seems inappropriate. The following are four common approaches to the changing role of training in the learning organisation:

- Open training - the creation of a flexible and accessible range of good quality courses. Obstacles which impede participation in training courses must be removed. Self-study, and the use of new technologies and requisites of the learning environment need to be arranged.

- Responsive training - directed towards the creation of an environment in which learners are stimulated to find their own approach to key problems. Managers and personnel should support each other in developing methods of handling critical tasks.

- On-site learning - this involves the dismantling of barriers between working and learning, by adding an educational dimension to functions, regulations and systems.

- Collective competence - this implies the enhancement of individual and group competence by providing adequate working aids and facilities. The main concern is performance and not learning (Jones \& Mann, 1992: 209).

\section{RESEARCH METHOD}

\subsection{Sampling}

For the purpose of this research project, the target population was chosen from South African organisations. All organisations with a training department or section, headed by a training practitioner or director, were regarded as the target population. The sample selected for this study consists of 374 training 
practitioners registered with the South African Board for Personnel Practices. It was felt that these training specialists would be able to provide objective and expert opinion with regard to implementing change through training in South African organisations. Only South African organisations were included and, therefore, nine foreign practitioners were excluded from the sample. It was felt that conditions in foreign organisations and the perceptions of their training practitioners may differ from their South African counterparts. The total sample size is therefore 365 .

\subsection{Survey design}

Based on the size of the sample (365), a mail survey by questionnaire was considered best suited to this study. The questionnaire consists of the following three sections:

- Section A: The learning organisation

- Section B: Training in the organisation

- Section C: Classification data (demographic profiles of respondents)

The type of ordinal scale used in Section A and B of the questionnaire is a fivepoint Likert-type scale. Section $C$ contains a nominal scale of measurement. Because this questionnaire had not been used in any previous research project, a pilot survey among 40 local organisations was conducted. Wherever possible, it was sent to human resources managers and training specialists for completion. The questionnaire was also sent to academics in the field of management, training, industrial psychology and statistics in order to identify problem areas and obtain suggestions. A total of 365 covering letters, questionnaires and return-paid envelopes were sent, with a reminder postcard following a week later. Questionnaires received from respondents were inspected, edited, coded and transferred for storage. The response rate for this survey is 54.25 per cent (198 questionnaires from a possible 365 included in the sample). The effective response rate (usable questionnaires) is 49.86 per cent (182 responses from a possible 365 ).

\section{SURVEY RESULTS}

\subsection{Descriptive statistics}

Figure 4 shows frequency distribution results of the research data for the learning organisation. 
Figure 4 Histogram of the frequency distribution results of section a of the questionnaire: the learning organisation

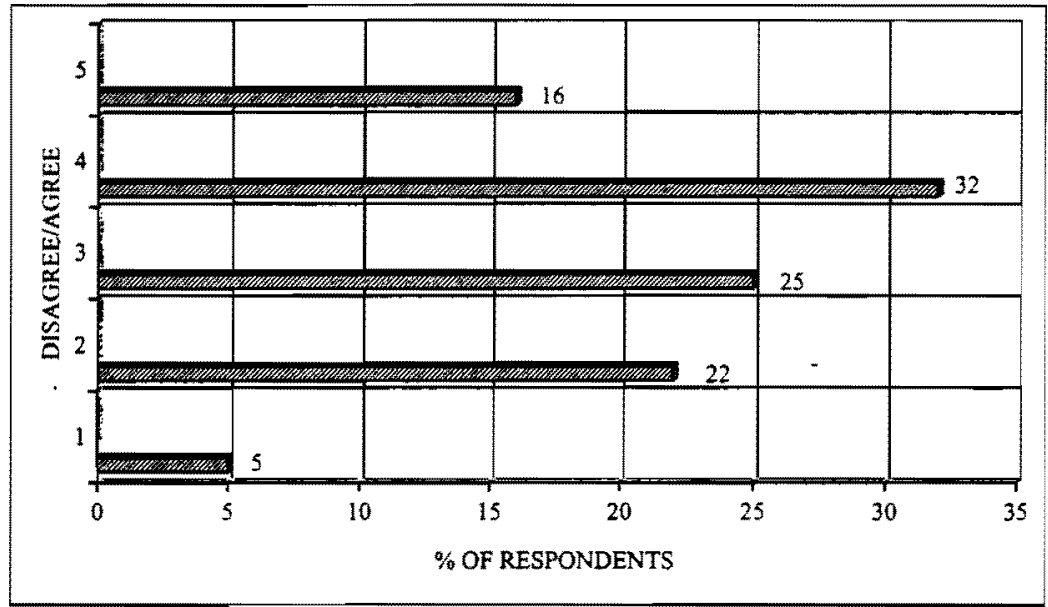

Figure 4 illustrates the frequency distribution percentages for the five points on the Likert-type scale of the questionnaire. It is shown that 27 per cent ( 5 per cent +22 per cent) of respondents tend to disagree with the statements regarding the learning organisation. Twenty-five per cent of respondents neither agree nor disagree with the variables concerning the learning organisation. Forty-eight per cent ( 32 per cent +16 per cent) of respondents indicate agreement with the aspects on the leaming organisation. It therefore appears that the majority of respondents agree with the variables regarding the learning organisation. In terms of the degree of asymmetry or skewness, the distribution of results seems to be negatively skewed (the tail of the distribution is to the left among the lower values of the variables). Kurtosis, which is a measure of the peakedness of the distribution, shows that the distribution is thicker and more peaked in the tail and can be classified as leptokurtic.

\subsection{Reliability of the variables}

The BMDP statistical software package (Programme 4M) was used to perform the factor analysis. Factors were extracted using Principle Component Analysis with Direct Quartimin Oblique rotation to allow for intercorrelations between factors. To confirm that all items load on the single factor, Cronbach's alpha was calculated. The reliability coefficient of Cronbach's alpha is 0.95 (Cronbach's alpha should be above 0.7 to indicate internal reliability). It can therefore be concluded that all factors are internally reliable (Cronbach's alpha > $0.7)$. 


\subsection{ANOVA}

Inferential statistics were used to make conclusions about the population using sample data and decisions about various hypotheses. An analysis of variance was conducted, which investigated the relationship between the following variables: organisational development (dependent variables) and training and classification data (independent variables). The ANOVA results, which indicate the relationship between the independent variables (classification data) and the learning organisation, are shown in Table 3.

Table 3 Analysis of variance results to investigate the relationship between the independent variables and the learning organisation

\begin{tabular}{|l|c|c|c|c|c|}
\hline \multicolumn{1}{|c|}{ Variable } & $\begin{array}{c}\text { Sum of } \\
\text { squares }\end{array}$ & $\begin{array}{c}\text { Degrees } \\
\text { of } \\
\text { freedom }\end{array}$ & $\begin{array}{c}\text { Mean } \\
\text { square }\end{array}$ & F-test & P-value \\
\hline $\begin{array}{l}\text { Number of } \\
\text { employees }\end{array}$ & 1.53527 & 2 & 0.76764 & 1.39 & 0.2508 \\
\hline Training department & 6.66008 & 1 & 6.66008 & 12.10 & $0.0006^{* *}$ \\
\hline Environment & 15.86708 & 2 & 7.93354 & 14.41 & $0.0000^{* *}$ \\
\hline Error & 94.13925 & 171 & 0.55052 & & \\
\hline
\end{tabular}

From Table 3, it can be deduced what is the relationship between the independent variables and the leaming organisation. It is clearly shown that $\mathrm{H}_{01}$ cannot be rejected, $F(1.171)=1.39 ; p>.05$. The number of employees (size of organisation) is not related to the learning organisation. There is a highly significant relationship between the existence of a training department and the learning organisation, $\mathrm{F}(1.171)=12.10 ; \mathrm{p}<.05$. The null hypothesis $\left(\mathrm{H}_{02}\right)$ can therefore be rejected $(p<.01)$ and the alternative hypothesis $\left(\mathrm{H}_{\mathrm{A}_{2}}\right)$ be accepted. There is thus a relationship between an organisation which has a fully developed training department and the learning organisation. The third null hypothesis $\left(\mathrm{H}_{03}\right)$ can also be rejected, $\mathrm{F}(2.171)=14.41 ; \mathrm{p}<.01$. It appears that there is a highly significant relationship between the environment in which an organisation operates and the learning organisation (accepting $\mathrm{H}_{\mathrm{A}_{3}}$ ).

The ANOVA results, which indicate the positive relationship between the independent variables (training) and the learning organisation, are presented in Table 4. 
Table 4 Analysis of variance results to investigate the relationship between the independent variables and the learning organisation

\begin{tabular}{|c|c|c|c|c|c|}
\hline $\begin{array}{c}\text { Independent } \\
\text { Variables }\end{array}$ & $\begin{array}{c}\text { Sum of } \\
\text { squares }\end{array}$ & $\begin{array}{c}\text { Degrees of } \\
\text { freedom }\end{array}$ & $\begin{array}{c}\text { Mean } \\
\text { square }\end{array}$ & F-test & P-value \\
\hline B1 & 50.5434 & 2.179 & 25.2717 & 57.83 & $0.0000^{* *}$ \\
\hline B2 & 37.1508 & 2.179 & 18.5754 & 36.29 & $0.0000^{* *}$ \\
\hline
\end{tabular}

From Table 4 it can be deduced what the relationship is between the learning organisation and the independent variables. It is clearly shown that the null hypothesis $\left(\mathrm{H}_{04}\right)$ can be rejected, $F(2.179)=57.83 ; \mathrm{p}<.01$. The alternative hypothesis $\left(\mathrm{H}_{\mathrm{A} 4}\right)$ can therefore be accepted: the facilitating role of training is related to the learning organisation. The null hypothesis, $\mathrm{H}_{05}$, falls within the rejection region, $\mathrm{F}(2.179)=36.29 ; \mathrm{p}<.01$ and suggests that $\mathrm{H}_{\mathrm{A} 5}$ can be accepted. There is a relationship between the role of training in managing organisational change and the leaming organisation.

\subsection{Correlations}

Table 5 highlights the correlation matrix of the variables or factors used in the study.

Table 5 Pearson product-moment correlation coefficients: section a and $b$ of the questionnaire

\begin{tabular}{|c|c|c|c|}
\hline Variable/factor & A1 & B1 & B2 \\
\hline A1 & 1.0000 & & \\
\hline B1 & 0.6867 & 1.0000 & \\
\hline B2 & 0.6733 & 0.8394 & 1.0000 \\
\hline
\end{tabular}

$\mathrm{Al}=$ The learning organisation

$\mathrm{Bl}=$ The facilitating role of training in the application of the learning organisation

$\mathrm{B} 2=$ The role of training in managing organisational change

In analysing the $r$-values of the correlation matrix in Table 5, the critical value used to interpret these $r$-values is: $r=0.1720 ; \mathrm{p}=0.01 ; \mathrm{n}=182$. All the calculated values of $r$ are greater than the critical value $(r>0.1720)$ which indicates that the relationship between the variables is statistically highly significant. 


\section{CONCLUSIONS AND RECOMMENDATIONS}

The importance of the leaming organisation is emphasized by the fact that organisations of the future will not survive without becoming communities of leaming. They have the capacity to facilitate the leaming of all their members and to adapt and change continuously. It is important to understand the process and nature of learning in order to facilitate the leaming and development of individual employees and, ultimately, the organisation itself. Organisational learning must equal or exceed the rate of change, otherwise the organisation will not survive. Training programmes should maximise the balance between learning and doing, and contribute to the development of the innovative capacity of the learning organisation. Analysis of the results investigating the relationship between the leaming organisation and the independent variables (classification data) produced the following conclusions:

- It appears that the size of an organisation, based on employment size, has no direct relationship with the leaming organisation $\left(\mathrm{H}_{01}\right.$ not rejected). Organisations of different employment sizes do not differ with regard to the facilitation of the learming organisation concept.

- There is a highly significant relationship between an organisation that has a fully developed training department and the learning organisation $\left(\mathrm{H}_{02}\right.$ rejected). Organisations that have a fully developed training department differ from those in which training activities fall under another function or department (regarding the learning organisation).

- The type of environment in which an organisation operates is related to the leaming organisation $\left(\mathrm{H}_{03}\right.$ rejected). Organisations operating in a dynamic environment (more inclined to leam and adapt to change) differ significantly from those operating in a moderate or static environment (as far as the learning organisation is concerned).

The following conclusions can be drawn from the relationship between the leaming organisation and training (independent variables):

- The facilitating role of training is related to the leaming organisation ( $\mathrm{H}_{04}$ rejected). Training can therefore be used to facilitate the implementation of the learning organisation concept.

- There is a highly significant relationship between the role of training in managing organisational change and the learning organisation $\left(\mathrm{H}_{05}\right.$ rejected). In using training to manage organisational change, the learning organisation concept can therefore be implemented.

Action should be taken to ensure that organisations become communities of leaming, because the way in which an organisation learns can be the key to 
innovation, profitability and competitiveness. A philosophy should be developed which is aimed at creating, mastering and transferring knowledge in the organisation in order to adapt and to change. It is important to understand the process and nature of learning in order to facilitate the learning and development of employees and the organisation itself. Management should establish appropriate conditions for leaming, reinforce desired leamed behaviour, provide environmental cues which encourage learning and a physical and emotional climate supportive of learning.

The leader should empower employees, encourage effective decision-making and inspire commitment through charismatic leadership. A learning organisation could be created by a leader who has vision, well-developed plans, a sense of inventiveness and is able to share information and implement all plans and strategies. It is vital to inculcate a culture of lifelong learning in the organisation to meet a continuous need for leaming. It is important to note that a fully developed training department, and the environment in which an organisation operates are related to the learning organisation. Attention should be given to the role of the training department and the environment of the organisation, and how the learning organisation could facilitate organisational change. The present survey revealed highly significant relationships between training and the leaming organisation. Action should be taken to use training in bringing about organisational change through the learning organisation.

The following are general guidelines and recommendations for building the learning organisation, as a means of facilitating training for change in an organisation:

- $\quad$ Provide learning strategies to improve knowledge and skills.

- Use participative policy-making practices.

- Implement flexible reward structures.

- Use front-line members as environmental scanners.

- Create a lifelong leaming climate in the organisation.

- Develop a shared vision which emerges at all levels in the organisation.

- Promote self-development for all members.

- Resolve conflict through collaborative learning and/or integration of diverse viewpoints.

- Formulate and implement ideas on all levels.

- Facilitate learning for all members of the organisation.

- Continually expand the innovative capacity of the organisation to create its own future.

- Continually experiment and improve the capacity of the organisation to deliver new goods and services to customers.

- Learn at a faster rate than that at which the organisation is changing. 
- Regard learning as part of working.

- Facilitate the process of transformation which enables the organisation to search for new ideas and/or opportunities.

\section{REFERENCES}

1 ARGYRIS, C. (1994) On Organizational Learning, Blackwell Business, Oxford,

2 BEARDWELL, I. \& HOLDEN, L. (1994) Human Resources Management: A Contemporary Perspective, Pitman Publishing, London.

3 BENCIVENGA, D. (1995) "Leaming Organizations Evolve in New Directions", HR Magazine, 40(10): 69-73.

4 DAWSON, S. (1992) Analysing Organisations, The MacMillan Press, Ltd., Hampshire.

5. DOBSON, P.C. \& TOSH, M. (1998) "Creating a Learning Organization: Training and Development in British Steel's Universal Beam Mill", Total Quality Management, 9(4/5): 66-70.

6 FISHER, D. \& TORBERT, W.R. (1995) Personal and Organisational Transformations, McGraw-Hill Co., London.

7 GORDON, J.R. (1996) Organizational Behavior: A Diagnostic Approach, Prentice-Hall, Inc., New Jersey.

8 GREENBERG, J. \& BARON, R.A. (1997) Behaviour in Organizations, Prentice-Hall, Inc., New Jersey.

9 HARRISON, R. (1998) "Move the Goal Posts", People Management, 4(2): 33 .

10 -HELLRIEGEL, D. \& SLOCUM, J.W. (1996) Management, South Western College Publishing, Ohio.

11 HENDRY, J., JOHNSON, G. \& NEWTON, J. (1994) Strategic Thinking: Leadership and the Management of Change, John Wiley \& Sons, Chichester.

12 JONES, M. \& MANN, P. (1992) Human Resource Development: International Perspectives on Development and Learning, Kumarian Press, Inc., West Hartford.

13 LESSEM, R. (1991) Total Quality Learning: Building a Learning Organisation, Basil Blackwell, Oxford.

14 LONGWORTH, N. \& DAVIES, W.K. (1997) Life Long Learning, Kogan Page, London.

15 LUTHANS, F. (1995) Organizational Behaviour, McGraw-Hill, Inc., New York.

16 MABEY, C. \& ILES, P. (1994) Managing Learning, Routledge, London.

17 MABEY, C. \& SALAMAN, G. (1995) Strategic Human Resource Management, Blackwell Business, Oxford. 
18 MARQUARDT, M. (1997) Building the Learning Organisation, Seminar conducted at Vista University, Port Elizabeth, 4 September 1997.

19 MARX, A.E. (1997) The Suggestion System as a Useful Instrument in a Learning Organisation, Paper delivered at National Productivity Institute Conference, Pretoria Technikon, November 1997.

20 MCSWEEN, D. (1995) “The Learning Organization? It's Child's Play", Management Review, 84(9): 6.

21 MORTON, C. (1994) Becoming World Class, MacMillan Press, Ltd., Hampshire.

22 NOER, D.M. (1997) Breaking Free: A Prescription for Personal and Orgnizational Change, Jossey-Bass Publishers, San Fransisco.

23 PEDLER, M., BURGOYNE, J. \& BOYDELL, T. (1991) The Learning Company: A Strategy for Sustainable Development, McGraw-Hill Book Company, London.

24 ROBBINS, S.P. (1996) Organizational Behavior, Prentice-Hall, Inc, New Jersey.

25 SENGE, P.M. (1997) The Fifth Discipline: The Art and Practice of the Learning Organization, Century Business, London.

26 SOLOMON, C.M. (1994) "HR Facilitates the Leaming Organization Concept", Personnel Journal, 73(11): 56-64.

27 SWIERINGA, J. \& WIERDSMA, A. (1992) Becoming a Learning Organisation: Beyond the Learning Curve, Addison-Wesley Publishing Company, England.

28 TOBIN, D.R. (1993) Re-educating the Corporation, Oliver Wight Publications, Inc., Essex Junction.

29 WICK, C.W. \& LEÒN, L.S. (1993) The Learning Edge: How Smart Managers and Smart Companies Stay Ahead, McGraw-Hill, Inc., New York. 